\title{
Complex investigation of thermophysical processes in plasma-jet spraying
}

\author{
Oleg P. Solonenko \\ Plasma Dynamics Department, Institute of Thermophysics \\ Siberian Branch of the USSR Ac. Sci., Novosibirsk, 630090, USSR
}

\begin{abstract}
The modern state of art concerning the equipment for gas thermal spraying, methods of diagnostics and modelling of high-temperature dust-laden jets and study of structure and properties of original and sprayed materials allows us to realize the complex experiment with the purpose to obtain a reliable information for the complete chain of phenomena occurring in the "original powder material - its injection into the flow - formation of dust-laden plasma jet - sprayed material coating" system. The development of the complex experiment conception required to create the corresponding methodology, physical and mathematical models, numerical methods, apparatus, hardware and software to extend our possibilities in fundamental and applied researches in the field of plasma dynamics of jet disperse system by means of rational combination of physical and computational experiments.
\end{abstract}

In this connection the survey of results which have been obtained at the Institute of Thermophysics of the Siberian Branch of the USSR Academy of Sciences in order to realize of above-mentioned approach is presented.

\section{INTRODUCTION}

Further development of science-extensive technologies for disperse material treatment requires complex investigations covering successively all chain links of forming the stable final product with the preset properties, the production of which is guaranteed not only under laboratory but industrial conditions as well.

Up to the present the above problem has not been solved completely for plasma spraying. This is related to variety and complexity of the processes occurring at gas thermal material spraying, unperfect and unsteady apparatus operation as well as the absence of scientifically substantiated principles of controlling many parameters for gas thermal spraying. The interaction between primary parameters defining the applicable materials, equipment and technology and secondary (output) parameters defining the spraying result is realized via a complex chain of thermophysical, physico-chemical and physico-mechanical processes in a burner, generated gas-disperse flow at its interaction with the base and material forming coating.

In most cases the possibility to realize the direct feedback between the primary and secondary parameters is absent in the modern technology of gas thermal spraying. That does not allow to obtain the coatings with preset properties on industrial scale with guarante. In this connection it is necessary to solve a complex of problems: 1) to create a highquality equipment providing precision control and maintaining the basic technological parameters of the process at the given level; 2) the develop the methods and apparatus for prompt diagnostics of the state for disperse and gas phases of the flow, as well as sprayed surface for the chosen technological regime; 3) to provide the control of material quality and properties both in the initial and finished states; 4) to create a complex of software for carrying out the computational experiment in parallel to a full-scale experiment; 5) to create the appropriate data bank, software for standard equipment envisaging the possibility of previous (using modelling) and experimental choice of necessary technological parameters.

The solution of these problems will allow to realize practically a complex experiment (CE) (refs. 1-3), at which a range of phenomena defining the gas thermal spraying in all the links of the chain, i.e. sprayed material, working gases, medium; generation of hightemperature flow; spraying process; formation of technological flow; process of sprayed 
material formation; produced coating, will be studied in interrelation using both direct measurements and computations.

On one side, the results of complex experiment is the only source of obtaining the reliable information on the processes occurring at gas thermal spraying as well as a basis for deepening the fundamental knowledge in this field and construction of physico-mathematical models. On the other hand, the complex experiment is the basis for creating software and technological certification of promising industrial equipment and, in our opinion, the only possible way to solve the problem of obtaining sprayed materials with preset properties. In future the complex experiment should become a basis of the development of scientifically substantiated standards on industrial sprayed materials, technology and equipment for gas thermal spraying. It is supposed that the creation of industrial equipment complexes with a common unit - module basis, which depending on specific applied problems will have different degree of complete set complexity, required level of technical certification and hardware, which are developed on the basis of complex experiment results, will be an optimal variant in future.

of late considerable successes in automation and robotization of plasma spraying process were attained due to the efforts of a number of companies (Metco, Plasmatechnic, MTS, etc). A substantial progress in creating high-intelligence analytical equipment providing new possibilities in studying the properties of sprayed materials and coatings is also noted. All this made the development of hard- and - software to be of high priority for prompt joint physical and computational experiments (ref. 4) in the technology of plasma jet spraying. The practical realization of subsystems 1) - 4) will allow to design purposefully the powder materials and devices for their injection into the plasma jet as well as improve spraying plasmatrons to obtain the optimal structure of production process by mutual correlation of separate links of "plasmatron - dust-laden jet - coating" chain while developing new unique materials (composite, amorphous, fine crystalline ones, high-temperature superconductors, etc. ).

Further the following problems are discussing: 1) creation of the computer-based experimental bench for complex diagnostics of heterogeneous high-temperature jets; 2) development of extended series of diagnostic methods are working on-1ine "experiment-computer" for measure of the most important parameters (velocity and temperature of phases, concentrational composition of gas, concentration of disperse particles and their size-distribution function); 3) development and practical realization of the problem-oriented mathematical technology for operative computer experiments and comparison the different models in the plasma dynamics of jets disperse systems; 4) creation of the effective numerical methods for study of different basic phenomena which take place in the theory and practice of plasma processing of the powder materials and first of all plasma spraying; 5) development and verification of physical and mathematical models for study of interphase momentum, heat and mass transfer in high-temperature jets of complex gas composition with an admixture of disperse particles; 6) investigation of a number of model problems of the nonstationary contact and conjugate heat transfer, are characterizing the "molten particle-base" interaction and temperature regimes of model rough elements.

Moreover the ways to increase the efficiency of plasma processing of powder materials by means of use of the nozzle-diffusers and more rational injection of powder into the plasma jet are discussing.

The obtained results of investigations and elaborations have allowed us to create the first version of conversational simulating complex "plasmatron-dust-laden jet-coating" for direct computational experiment in plasma spraying.

And, finally, presented are the possibilities of complex experiment in plasma spraying which has permitted us to extend our knowledge about the processes affecting basically the structure and properties of sprayed materials.

\section{COMPUTER-BASED EXPERIMENTAL BENCH}

A computer-based experimental bench (Fig. 1) consists of (refs. 5, 6): 1) physical rig, allowing one to investigation both one-phase and high-temperature dust-1aden jets of complex gas composition; 2) an extended series of diagnostic methods to measure the most important parameters (velocity and temperature of phases, concentrational composition of gas, concentration of disperse particles and their size-distribution function); 3) a complex of hardware and software components for automatic acquisition, storage, processing and computer graphic of experimental data as well as control of experiment, if required. 


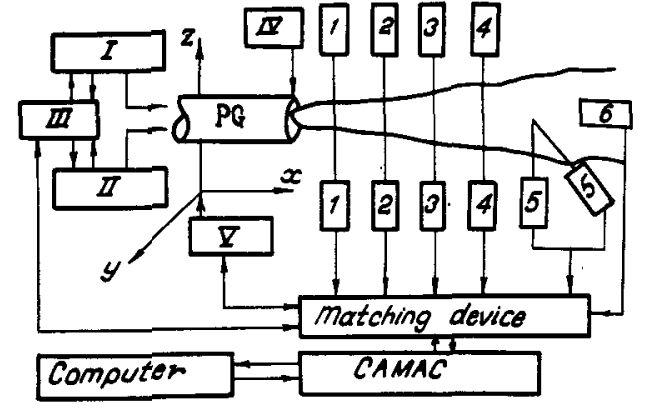

Fig. 1. Block-diagram of computer-based bench: I, II - gas-water-energy supply system; III system to control and regulate regime parameters; IV - metering device for powder materials; V - control system for coordinate unit displacements; 1-6 - diagnostic apparatus: 1 - Laser-Doppler anemometer; 2 - small angle scattering method; 3 - emission-absorption method; 4 - tomograph; 5 - method for measuring simultaneously particle velocity and temperature; 6 - calorimetric probe.

Among the methods of diagnostics which are employed and developed at the bench one should particularly consider three of them, which are of considerable interest for carrying out the complex experiment in plasma-jet spraying. Water-cooled probes (enthalpy meters) in combination with the methods to measure composition in multicomponent mixtures (gas chromatography) are applied to study experimentally the velocity, temperature and concentrational heterogeneities in the steady-state one-phase (multicomponent) highenthalpy gas jets.

A computer-aided calorimetric probe with suitable pickups, software and hardware components (Fig. 2) has been developed by us to provide jet diagnostics, applying the similar probes in real-time on-line with computer (ref. 7). The scheme of measurements is chosen a standard.

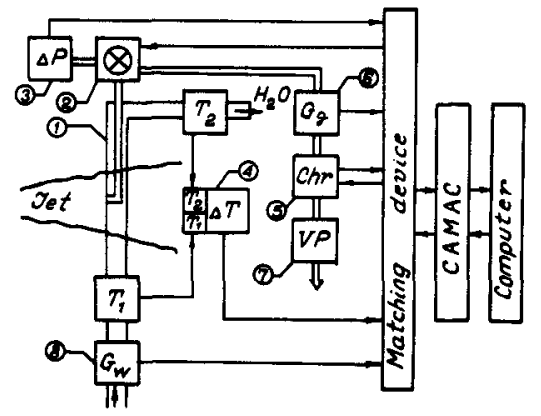

Fig. 2. Computer-aided calorimetric probe. 1 - enthalpy meter; 2 - electromagnetic valve for operating regimes; 3 - pressure strain gauge; 4 - differential thermometer; 5 - chromatograph; 6 - pickup for measuring flow rate of gas sampling; 7 - vacuum pump; 8 - pickup of water flow rate.

The analog output signals of all measuring pickups (including the output signal of chromatograph) are converted to standard level and in the process of measurements they arrive into micro-computer Electronika-60.

The enumerated data are sufficient to calculate the local velocity and flow temperature on the assumption of local thermodynamic equilibrium (LTE) having used the tables on gas properties which are stored in the external memory of computer.

The creation of computer-based enthalpy probe allows us even now to come close to the solution of important applied problem, $i$.e. the construction of data bank on spraying plasmatron jets. Besides its application in the regime of prompt mass experiments allows us to optimize the geometry of the exit nozzle - anode to form the required gas dynamic structure of plasma jet, which is the basic technological zone of sprayed material treatment.

Frequently heterogeneous plasma jets tharacteristic for the processes of production and treatment of powder materials do not possess axisymetric temperature and phase velocity, gas component or dispersive particle fields. Their size distribution function may be noninvariant relative to rotation around the jet axis, etc. For example, temperature fields of plasma carrying flow and hence inertial admixture, can have no axial symetry basically due to: 1) mainly one-sided anode arc spot; 2) nonaxisymetric injection of powder material into plasma jet. 
It is evident that in the enumerated cases it is impossible to use the methods of diagnostics which are based on the experimental data processing using the Abel inversion, but the application of the local measuring methods increases to a large extent the duration of the experiment.

In similar cases tomographical methods are rather promising, in particular, the emission plasma tomography method (ref. 8) for measuring the temperature fields. The survey of investigations in the field of plasma tomography can be found in (refs. 8, 9), but the schemes of emission plasma diagnostics (two- and - six aspect), which are used in the experiment, are considered in (ref. 10). It should be noted that as applied to lowtemperature plasma most known publications is devoted to methodical and computational aspects of this diagnostical method and the papers on creation of completely computer-based versions of emission tomographs are few in number. According to the paper (ref. 11), as applied to plasma jet, into which the cold gas is injected normal to its axis, the first investigation with the application of tomography methods was carried out in (ref. 12), where the temperature fields in the jet sections were measured by recording the jet radiation from 4-6 cross projections.

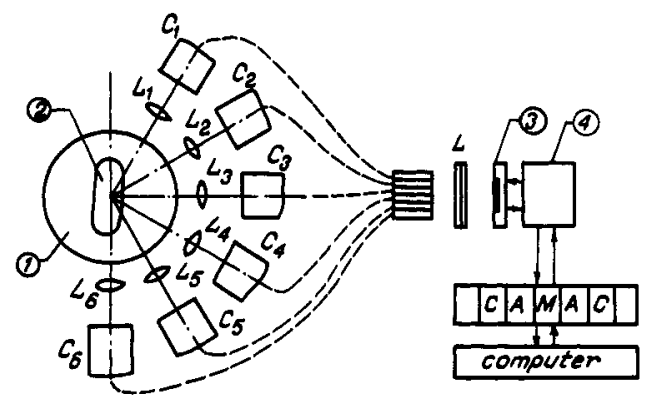

Fig. 3. Principle scheme of computerbased plasma tomograph. 1 - jet section; 2 - high-temperature core; 3 - photodiode matrix; 4 - buffer memory.

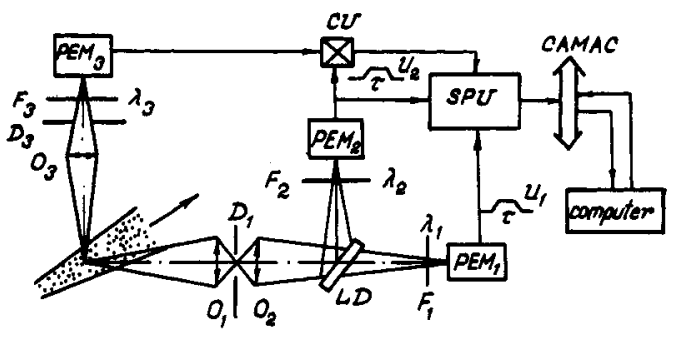

Fig. 4 .

Fig. 3 shows the layout of computer-based plasma tomograph. The jet section under study is focused using short-focus lens $L_{i}, i=\overline{1,6}$ from 6 aspects to the end surfaces of corresponding light guides $C_{i}, i=\overline{1,6}$, the response ends of which are bundled in a common unit. The observable picture is focused using the cylindrical lens $L$ to the receiving surface of photo-diode-matrix. Similar to (ref. 13) while carrying out the spectral investigations the image from the outlet end surfaces of light-guide unit is projected to the inlet slot of the spectrograph, and matrix is placed at the outlet of the latter. The only reliable method of image formation in this situation is the maximum quick inquiry of information from photo-diode-matrix with read-in into operative memory of the computer. Then either information is directly processed and isotherms are displayed in the studied jet section or the frame is recorded in the external memory of the computer.

The developed tomograph allows us to investigate the degree of deviation from the axial symmetry of jet temperature field at the nozzle of a plasmatron as well as evaluate the effect of nonsymmetric injection of cold gas seeded into the main plasma jet.

The development of diagnostic apparatus, permitting to record simultaneously several parameters characterizing of disperse particles in plasma jet, with satisfactory spartial resolution is of considerable scientific and practical interest.

In this connection, attemps have been made to devise and adapt at the bench the method to measure simultaneously the velocity and temperature of disperse particles in hightemperature flow.

This problem has been solved (refs. 14, 15) by applying the method of particle diagnostics by their thermal radiation (Fig. 4). The main optical section is designed as a single unit to measure velocity and temperature, i.e. velocity is measured from the duration of an output signal of one of the PEMs of a two-colour pyrometer which makes it possible to obtain simultaneously the temperature and velocity of single particle with fixed size. 
The gist of the method is as follows. The image of a moving particle in the main optical section is projected by objective $0_{1}$, of which high demands concerning chromatic aberration are made, into the plane of a slot which is perpendicular to the assumed direction of the particles. Then the image of slot $D_{1}$ is projected in the form of orthogonal beams with equal intensity by means of objective $\mathrm{O}_{2}$ through a beam splitter (BS) on the photocathodes of $\mathrm{PEM}_{1}, \mathrm{PEM}_{2}$, in front of which light traps $\mathrm{LT}_{1}$ and $\mathrm{LT}_{2}$ are placed that pass the narrow bands of the radiation spectrum with wavelengths $\left(\lambda_{1}\right.$ and $\lambda_{2}$, respectively) in the centre.

An additional optical section is used for spatial localization of the measurement range. The output signals of $\mathrm{PEM}_{1}$ and $\mathrm{PEM}_{2}$ arrive at the signal processing unit (SPU), if the control unit (CU) only confirms that the image of the particle has got into the field of both optical sections simultaneously.

One should note the main restrictions inherent to this method: 1) the measurement of particle surface temperature in the near-axis regions of plasma jet for small distances from the nozzle, where plasma radiation is high, is rather problematic; at the same time, this zone is of great interest since exactly in it the particles injected into plasma flow usually undergo the stage of intensive heating, but in a number of cases - also phase transitions; 2) there exists a limit in the particle sizes, below which the useful signal becomes comparable with the background lighting as well as noises of primary converters and electron apparatus; 3 ) the lower limit of recorded particle temperature is limited by $1500 \mathrm{~K}$ due to infinitesimal signal amplitude at the ADC inlet; 4) at rather high velocities of emitting particles or an increase in the local character of measurements the requirements to temperal resolution of ADC used for primary data input to microcomputer, increase; this is especially important for reliable determination of the particle size by differentiating the front of the signal increasing or decreasing.

From the methodica1 point of view the further development and improvement of the methods based on recording the intrinsic thermal emission of the particles should take into account the following: 1) with intensive particle evaporation due to the presence of vapour "shirt" near its surface, loss and redistribution in the spectrum of its surface emission energy may occur; 2) it is necessary to take into account the abnormal nature of the particle emission in the region of intensive "melt-solid" phase transition depending on the extent of transition nonequilibrium or cooling rate; this fact is mentioned by some authors (refs. 16-18), and the substantiation of the observed abnormal electromagnetic energy radiation is presented in (ref. 18), where it has been shown that crystallization conditions affect the optical constants of polycrystalline particles and their emissivity is higher than that of monocrystalline ones.

The experience of the bench operation allowed us to formulate a number of requirements concerning its further development; 1) it is necessary to improve individual methods of measurements to extent their functional possibilities by using in (refs. 14, 15) of polychromatic pyrometry with simultaneous measuring both velocity and concentration of particles and their sizes as well as to extend the possibilities of LDA for investigation of turbulent characteristics of the flow; 2) it is promising to develop complete multifunctional computer-based apparatus combining several previously approbated methods of measurements; 3) it is of high priority to develop and improve hard- and software to carry out computer based experiments on - line with computer in conversational mode.

The diagnostic methods operating on-line with computer and applied at present under laboratory conditions with their further improving may become an effective tool to control complex parameters of technological processes.

\section{CONVERSATIONAL SIMULATING COMPLEX FOR DIRECT COMPUTATIONAL EXPERIMENT IN GAS THERMAL SPRAYING}

The problem-oriented core of the complex experiment in gas thermal spraying is a conversational simulating complex (CSC) "high-temperature flow generator-dust-laden jetcoating" (ref. 19). This is a multipurpose, constantly progressing complex of methodical, algorithmic, software and information means aimed at substantial increase in the efficiency of learning, investigations and developments for the technologies of gas thermal coating spraying. The creation of such complex incorporating the data bank for appropriate subjectmatter fields in a compressed form will be useful by far not only for fundamental investigations but applications as well. It will enable the inverse link between the specific practical demands and research laboratories, and stimulate investigations of some scanty investigated problems providing uniform accuracy of the calculation of either phenomena. 
CSC is a problem-oriented complex of programs. It is intended for various categories of users. On the one hand, it should be rather simple to operate, on the other hand, it should be multipurpose since it is necessary at least for: 1) studying momentum, heat and mass transfer processes on the basis of numerical experiment; 2) joint physical and computational experiment; 3) approbation and mutual comparison between different physicomathematical models and experimental data; 4) training of specialists engaged in technologies of powder material treatment, including gas thermal spraying; 5) solving specific applied problems, including optimization of regime process parameters.

In its turn, CSC orientation for a wide range of users and simplicity of its operation require a thorough consideration of the following problems: 1) the development of simple and effective architecture of the program packages using structuring method and modularity principle; 2) the development of internal data structure providing convenience in programming of individual complex subsystems responsible for simulation of either processes included in the scope of investigations as well as allowing its broadening; 3) the choice and development, if necessary, of sufficiently reliable and universal numerical methods and creation of software on their basis enabling to synthesize different schemes of computational algorithms; 4) the development of input conversational language close to natural description of the problems of the class considered; 5) the provision of the possibility to operate with reference data banks constituting the information supply of the complex; 6) the creation of service modulus set to process the computational information for a high-speed representation and interpretation of the results obtained; 7) the provision of complete error diagnostics throughout the operation of the complex.

The analysis of the processes constituting the basis of gas thermal spraying allows us to formulate a number of problems facing the direct computational experiment which should be included in the functional scope of CSC in the form of the following subsystems:

1) Generation of high-temperature flow (plasmatron with stationary arc; pulse plasma generator; electric arc metalizator; detonation gun; gas heater);

2) Introduction of sprayed material (injection of powder material with the help of gascarrier; bar or wire spraying; powder wire spraying);

3) Formation of high-temperature dust-laden flow (interphase momentum, heat and mass transfer in the medium of reduced, normal and elevated pressure under the conditions of controllable or incontrollable atmosphere taking into account, the prehistory of disperse material injection and complex aggregation state of the particles in the flow);

4) Formation of spraying material (interaction between high-temperature gas disperse flow, including single particles with pretreated base, intermediate sublayer or the basic coating; thermal state of a base in the process of spraying);

5) Subsequent treatment of sprayed material in order to change its structure (thermal annealing; laser or electron beam, scanning electric arc or plasma jet effect; heating by high-frequency current).

In a number of cases taking into account the simultaneous running of the process, subsystems 1) - 3) as well as 4) - 5) should ensure the possibility of complete or partial matching. Besides CSC in the development should provide the possibility of predicting the most important qualitative characteristics of coatings (edhesion and cohesion; thermal conductivity; residual stresses; porosity, thickness and structure; density hardness; electrical conductivity; optical properties).

In our opinion, one of the important requirements imposed for CSC is to provide the possibility to carry out computational experiment using the models with different degree of complexity and hence adequacy while describing either processes constituting the chain of the phenomena. Hence it is expedient to simultaneously develop the physico-mathematical models and appropriate software constituting the scope of CSC in the following directions: 1) the development of analytical methods providing the solutions of certain model problems in the final form; 2) obtaining approximate analytical engineering solutions; 3 ) direct computational experiment using the models with different degree of complexity and dimensionality. A reasonable combination of these three approaches allows us to promote the optimization of the regime parameters of the processes as it may be implemented in two stages: 1) high-speed computation of the set of model problems permitting exact approximate analytical or rough numerical solution to obtain extreme estimates as well as to investigate qualitative behaviour of the desired function and localization of the optimization region; 2) subsequent particularization of the process behaviour in the whole using more complete models allowing to obtain a detailed information (e.g. while investigating the "melted particle-surface" interaction, of interest is the detailed information on phase transition, the possibility to predict the probability of nucleation, the size of nuclei, the rate of super-cooling in separate zones, etc.). 


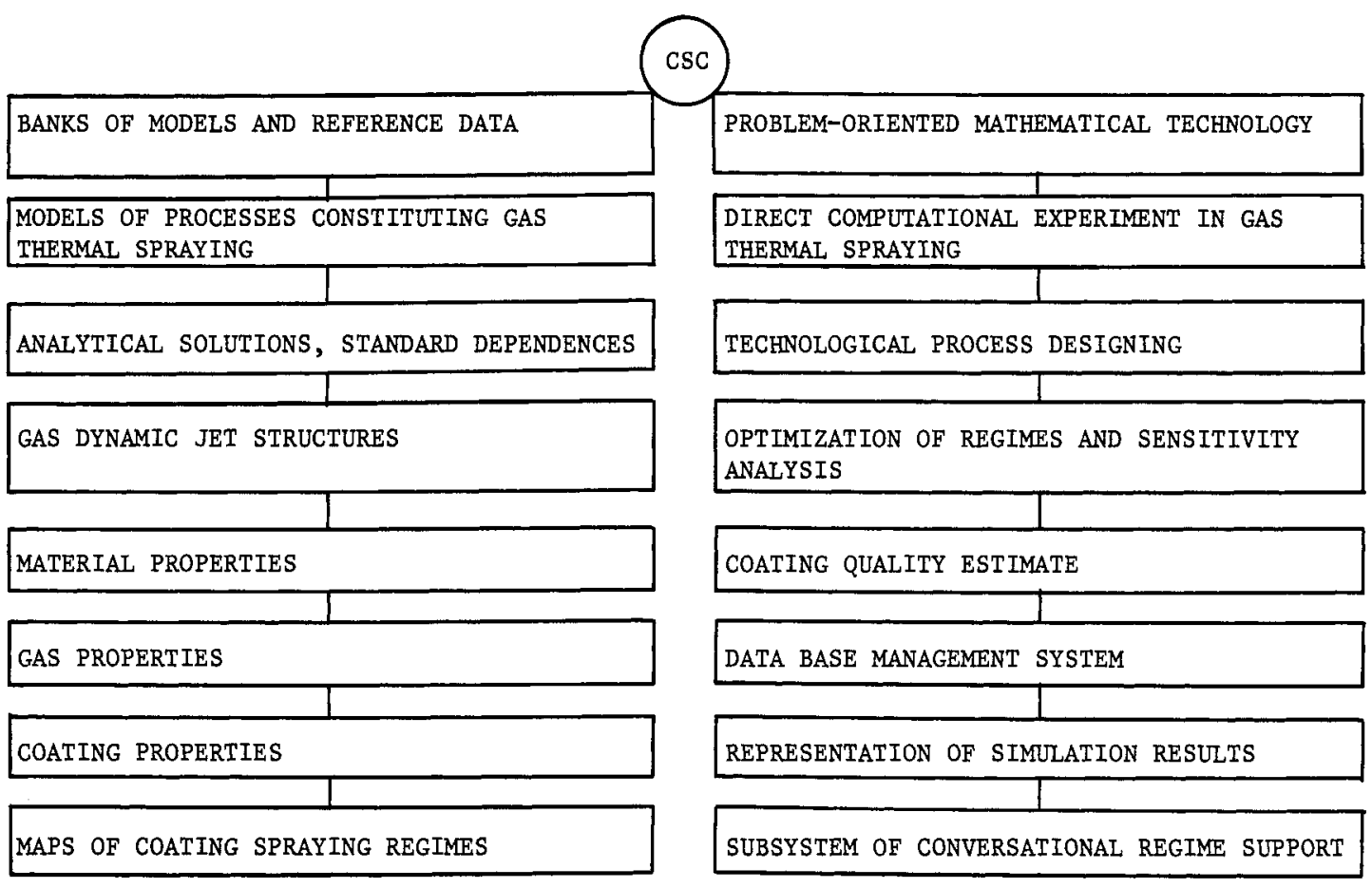

Fig. 5. Software and Information Support of CSC.

It is expected that CSC should also incorporate a number of subsystems (Fig. 5) offering the possibility to implement: 1) multiparameter optimization of regime parameters for the spraying process with due account of the applied physico-mathematical model "high-temperature flow generator - dust-laden jet - coating" (spraying distance; supplied power; composition of gas-carrier and plasma forming gas and their flow rate; geometry of generator exit nozzle; location and parameters of spraying material injection into technological process, etc.); 2) analysis of coating characteristic sensitivity to variations of determining parameters and physical criteria; sensitivity analysis is widely employed in most iterative procedures related to the parameter identification, the choice of optimal conditions to carry out physical and technological experiments as well as the regimes of optimal control (refs. 20, 21); besides the results concerning the investigation of coating quality sensitivity problems are of independent interest as they allow us to set the quantitative relations between the perturbations of external (regime and structural) parameters of the process and the desired quality function at the level of physico-mathematical model that is important for specialists involved in designing the equipment and developing new sprayed materials as well as process engineers at the stage of final operational development at the base installation; 3) start-to-finish simulational designing of technological process taking into account: optimal set of regime parameters obtained; dynamics of topography spot spraying onto the point (computated or obtained from the experiment); distribution of velocities, sizes, concentration and aggregation particles state with respect to spraying spot, geometry of sprayed product surface; desired thickness of coating; sequence of deposition and possible intermediate treatment of its separate layers; utilization factor of sprayed material; kinematic characteristics of the applied manipulators for mutual displacement of spraying device and product, etc.

\section{DEVELOPMENT OF THERMOPHYSICAL FUNDAMENTALS FOR PLASMA-JET SPRAYING}

4.1 Methods of powder injection The efficiency of the processes of disperse material treatment in plasma jets is determined to a large extent by the flow structure at initial region of a high-temperature dust-laden jet. This structure depends on the method and place of powder injection into plasma flow as well as conditions, under which the processes of interphase heat and momentum transfer proceed while forming gas disperse technological flow. 
Since the turbulent Prandt 1 number in a free turbulent plasma jet $\operatorname{Pr}=\mu_{f t} C_{p f} / \lambda_{f t}$, then the possibilities of increasing the efficiency of heating the powder at its injection under the nozzle exit are limited due to a quick cooling of carrying flow owing to intensive mixing with cold ambient. Besides the inhomogeneity of velocity and temperature fields in a jet, which accurs in this case, results in the appearance of the particles in its sections, which are in different aggregation states (ref. 1). Therefore in most technological processes based on plasmatrons with internal electrical arc the powder is injected in front of the exit nozzle. Here several variants and their combinations are possible: 1) transversal injection into nozzle-anode behind the zone of arc root; 2) powder injection into the plasmatron channel together with the main working gas; powder injection using additional carrier gas between cathode and anode is the modification of this method; 3) axial particle injection through cathode using the carrier gas.

The first method at present is apparently most widely used due to its simplicity and adaptability to perform. Here a one-sided material injection through an injecting tube of some diameter $D_{i}$ is generally used, owing to which an increase in the coefficient $k=G_{p} / G_{f}(m)$ of flow loading by disperse phase $\left(G_{p}, G_{f}(m)\right.$ are the powder consumption and the main plasma forming flow rate) is rather problematic due to the necessisity of simultaneous increase in carrier gas flow rate without considerable supercooling of plasma jet and increase of the particle concentration in the vicinity of the place of their injection. In this case one should obey the condition $D_{i} / D_{c}<10^{-1}$, where $D_{c}$ is the diameter of the plasmatron channel. Another severe shortcoming is the absence of axial symmetry of technological flow which is organized in such a manner that complicates the prompt computational and experimental optimization of spraying process.

The advantage of the second method is the potential possibility to increase substantially the efficiency of the process of powder material treatment, but in this case the particle deposition on the cold walls of the plasmatron channel is possible. In the zone of arc operation the powder evaporation is possible while particles can be cold near the channel wa11. Hence while using plasmatrons with self-stabilizing arc length (small length of thermal treatment region) particles will be inhomogeneous in the exit section of the nozzle with respect to velocities and temperatures.

And finally, the third variant as compared to the second one is more preferable from the point of view of gas dynamic considerations since in this case it is possible to exclude completely the particle deposition on the channel walls and control at the same time the degree of particle flow concentration. However the common serious shortcoming of the second and third injection methods, which correspond essentially to the reactors of combined type, is the direct effect of disperse phase on the regime of arc operation. The latter requires to carry out the investigations aimed at studying V-A characteristics and regimes of stable arc operation in the presence of disperse phase and its vapours. However the solution of this problem is for from completion.

Thus doing justice to two last variants of sprayed powder material injection, in our opinion it is most promising that further modification of plasma-jet spraying technology and, first of all, an increase in efficiency of the process should be based on the module approach based on the following three principles (ref. 22), which is shown in Fig. 6:

- development, investigation and application of plasma generators with interelectrode inserts providing guaranteed diffusive arc spot on the anode that will allow to generate stable axisymmetric plasma flows with well developed profiles of temperatures and velocities;

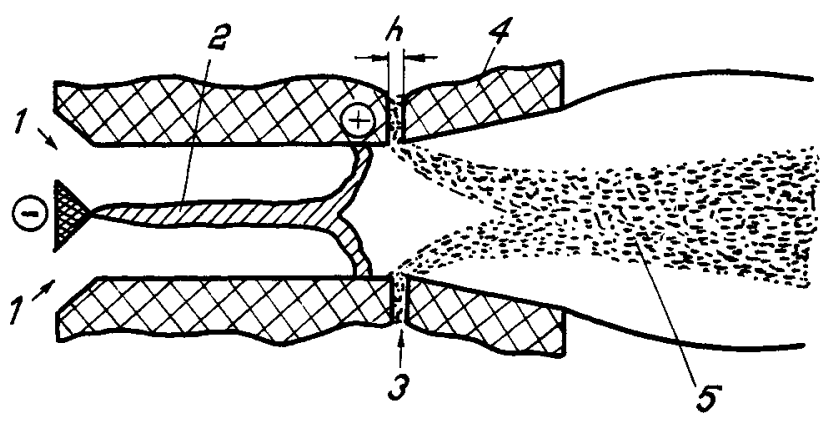

Fig. 6. Promising scheme of plasma-jet spraying.

1 - axial injection of plasma forming gas; 2 - electric arc with diffusive spot on anode; 3 - radial-annular injection of powder; 4 - diffusor; 5 - axisymmetric high-temperature dust-laden jet (h - width of radial-annular slot). 
- modification of powder material injection systems by their radial annular injection behind the anode arc root that will allow to increase essentially the efficiency of spraying with respect to powder and provide the conditions for its efficient subsequent thermal treatment;

- application of removable extentions including diffusors with hot wa11s, which provide efficient thermal treatment of the powder material and its protection from harmful effect of surroundings (gas saturation, oxydation, decomposition, etc.).

Successive development of this approach seems to be promising not only for technology of plasma-jet spraying but also for other science-extensive processes of treatment and production of disperse materials (spheroidization, dispersity, extractive metallurgy, etc.), since due to axisymetrical character of gas disperse technological flow generated in this case its prompt optimization is possible on the basis of joint physical and computational experiments (ref. 4).

In (ref. 22) an engineering technique for calculation of the particles thermal treatment with one-sided and radial-annular injection of the powder is suggested which takes into account the heat losses by carrier flow depending on the coefficient $k=G_{p} / G_{f}(m)$ of its loading by disperse phase. This model allows us to make comparative estimates of heating efficiency and maximum productivity $k_{\max }$ for two methods of powder injection into a nozzle-diffusor with due account of the required particle composition. Under heating efficiency we understand the ratio between the flow rates of heat in the disperse phase in the exit of nozzle and initial plasma flow. Table 1 shows the results of such comparison while treating the particle AI 0 (diameter $D_{p}=50 ; 100 \mathrm{mcm}$ ) in nozzle-diffusor of a fixed length $\mathrm{L} / \mathrm{D}_{\mathrm{C}}=3.7$ for three flow rates of plasma forming gas (air, $D_{C}=10^{-2} \mathrm{~m}, \mathrm{~T}_{\mathrm{fo}}=6000 \mathrm{~K}$ ): $\mathrm{G}_{\mathrm{f}}^{(\mathrm{m})}=0.5 \cdot 10^{-3} ; 1 \cdot 10^{-3}$; $2 \cdot 10^{-3} \mathrm{~kg} / \mathrm{s}$.

TABLE 1 . The comparison of two methods of powder injection

\begin{tabular}{|c|c|c|c|c|c|c|}
\hline \multirow{2}{*}{ Tipe of injection } & \multicolumn{2}{|c|}{$G_{f}^{(m)}=0.5 \cdot 10^{-3} \mathrm{~kg} / \mathrm{s}$} & \multicolumn{2}{|c|}{$G_{\mathrm{f}}^{(\mathrm{m})}=1 \cdot 10^{-3} \mathrm{~kg} / \mathrm{s}$} & \multicolumn{2}{|c|}{$G_{f}^{(m)}=2 \cdot 10^{-3} \mathrm{~kg} / \mathrm{s}$} \\
\hline & $\begin{array}{l}D_{p}=50 \mathrm{mcm} \\
W_{r p o}=4.5 \mathrm{~m} / \mathrm{s}\end{array}$ & $\begin{array}{l}D_{p}=100 \mathrm{mcm} \\
W_{r p o}=2.3 \mathrm{~m} / \mathrm{s}\end{array}$ & $\begin{array}{l}D_{p}=50 \mathrm{mcm} \\
W_{r p o}=6.5 \mathrm{~m} / \mathrm{s}\end{array}$ & $\begin{array}{l}D_{p}=100 \mathrm{mcm} \\
W_{r p o}=3.45 \mathrm{~m} / \mathrm{s}\end{array}$ & $\begin{array}{l}D_{p}=50 \mathrm{mcm} \\
W_{\text {rpo }}=10 \mathrm{~m} / \mathrm{s}\end{array}$ & $\begin{array}{l}\mathrm{D}_{\mathrm{p}}=100 \mathrm{mcm} \\
\mathrm{w}_{\mathrm{rpo}}=5.3 \mathrm{~m} / \mathrm{s}\end{array}$ \\
\hline$\frac{\text { One-sided }}{\left(D_{i}=10^{-3} \mathrm{~m}\right)}$ & & & & & & \\
\hline$\eta^{(1)}$ & 0.023 & 0.006 & 0.02 & 0.0003 & 0.015 & 0.0003 \\
\hline$k_{\max }^{(1)}$ & 0.138 & 0.038 & 0.124 & 0.002 & 0.084 & 0.002 \\
\hline$n^{(2)}$ & 0.009 & 0.000003 & 0.004 & - & 0.0003 & - \\
\hline $\begin{array}{c}\mathrm{k}_{\max }^{(2)} \\
\text { Radial-annular } \\
\left(\mathrm{h}=10^{-3} \mathrm{~m}\right)\end{array}$ & 0.041 & 0.00001 & 0.02 & - & 0.001 & - \\
\hline$\eta(1)$ & 0.57 & 0.31 & 0.54 & 0.22 & 0.47 & 0.08 \\
\hline$k_{\max }^{(1)}$ & 3.31 & 1.18 & 3.19 & 1.27 & 2.76 & 0.49 \\
\hline$\pi$ & 0.30 & 0.0001 & 0.24 & 0.00008 & 0.14 & - \\
\hline$k_{\max }^{(2)}$ & 1.32 & 0.0006 & 1.08 & 0.0004 & 0.61 & - \\
\hline
\end{tabular}

The velocity $W_{\text {rpo }}$ of powder injection in each specific case was chosen from the condition that a single and radial-annular jet along its trajectory does not intersect the flow axis and at the diffusor exit is at a distance of $r=0.05 \cdot \mathrm{D}_{c}$ from axis. Superscripts 1,2 are corresponding to the values $\eta$ and $k_{\max }$ for the cases when it is necessary only to melt the particles or melt and overheat to the temperature $\mathrm{T}_{\mathrm{p}}^{*}=\left(\mathrm{T}_{\mathrm{p}}, \mathrm{m}^{+} \mathrm{T}_{\mathrm{p}, \mathrm{b}}\right) / 2$, where $\mathrm{T}_{\mathrm{p}, \mathrm{m}}, \mathrm{T}_{\mathrm{p}}, \mathrm{b}$ is the material melting and boiling temperatures, respectively. As one can see from the data presented the radial-annular method of powder injection essentially excels the standard enjection method both in efficiency and productivity.

4.2 Modelling of dust-laden plasma jets The predominant effect of interphase momentum, heat and mass transfer processes is the peculiarity of the plasma dynamics of jet disperse system. There exists a close interrelation between gas dynamics of heterogeneous flow and phase and chemical transformations occuring in it. The diversity of phenomena and factors related to the processes of plasma jet treatment of powder materials is discussed in (refs. 5, 11, 23, 24).

A considerable number of papers is devoted to simulation of interphase momentum, heat and mass transfer in plasma jets with an additive of disperse particles. Their survey is given in (refs. 3-5, 11, 23-25). Depending on the method of disperse phase description, all available models can be divided into two types: Iagrangian and Eulerian ones. The 
Lagrangian approach (or "trajectory" method) combines in itself the Eulerian description for carrying phase and the Lagrangian one for disperse phase. The solution of motion and heat - mass transfer equations for a single particle in gas flow with precomputed (commonly two-parameter turbulence model) or experimentally measured velocity and temperature field is of more physical nature, and is readily realized in the case of rather inertial particles when their turbulent diffusion can be neglected. The situation is more complicated when it is necessary to take into account interphase turbulent momentum and heat transfer as the stochastic nature of equations incorporating the actual values of phase velocities and temperatures causes statistical modelling of the process with subsequent averaging of velocities and aggregation state for the particle ensemble. In this case to increase the accuracy of computational experiment, one should increase the number of test particles, but to take into account their inverse effect on carrying flow, one should correct the velocity and temperature field of carrying flow with the help of iterations in each temporal layer using the obtained parameters of disperse phase. All this results in the increase of computational bulk.

Besides the calculation of interphase heat and mass transfer requires the knowledge of the particle surface temperature which in a number of practically important cases can be determined correctly only by simultaneous solving the internal problem unsteady-state thermal conductivity, i.e. with due account of real temperature distribution inside the particle. The latter also complicates significantly the computation and is the reason why most investigations, for example, (refs. 11, 23, 25-27) have been carried out for mean mass temperature of the particles. The known investigations into the internal problem of unsteady-state thermal conductions (refs. 28, 29) are based on a net method that makes computational programs inefficient.

Taking into account the important of further development of Lagrangian models we have developed (ref. 3) more effective method than finite-difference one for computation of complex particle aggregation state with due account of diverse situations realized in the processes of plasma jet treatment of powder materials (simultaneous melting and evaporation of a particle; its complex recrystallization when two fronts move towards each other; treatment of cladded powders including thermoreacting ones; account of particle porosity or presence of microdisperse inclusions in it; internal diffusion, including gas absorption etc.). All this will extend the possibilities of CSC and decrease the time of computational experiment using Lagrangian models.

Let us illustrate the basic details of the method on the example of the standard boundaryvalue problem for nonstationary thermal conductivity equation

$$
\frac{\partial}{\partial F_{0}} \bar{\rho}_{p} \bar{c}_{p} u_{p}=\frac{1}{\eta^{2}} \frac{\partial}{\partial \eta} \eta^{2} \bar{\lambda}_{p} \frac{\partial u_{p}}{\partial \eta} \text {, }
$$

which should be solved in the region $\eta \in\left(\bar{r}_{1}(F O) ; \bar{r}_{2}(F o)\right)$ where $\bar{r}_{1}$ can be a coordinate either of the particle centre or internal melting front (crystallization) or internal, or external surface of particle material rupture due to its volumetric shrinkage, or external melting front (crystallization). On the other side $\bar{r}_{2}$ for enumerated cases can be accordingly a coordinate either of the internal melting front (crystallization) or internal, or external surface of particle material rupture, or external melting front (crystallization), or the particle surface. The following dimensionless variables are used above Fo=a $(s) t / R^{2}-$

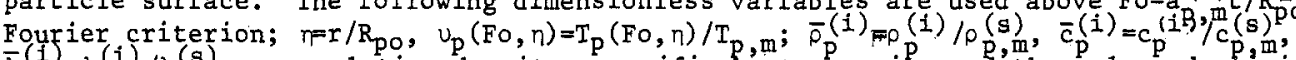
$\bar{\lambda}_{\mathrm{p}}=\lambda(i) / \lambda(\mathrm{s})$ are relative density, specific heat capacity and thermal conductivity of the material in the $i-t h$ state ( $i=s, m$ for solid and liquid states, respectively) corresponding to the local temperature $u_{p}(F o, n)$; subscript " $m$ " idenotes that parameter is taken at material melting temperature; $a_{\mathrm{p}, \mathrm{m}}^{(s)}=\lambda\left(\mathrm{p}, \mathrm{m} /(\rho), \mathrm{s}, \mathrm{m}, \mathrm{c}_{\mathrm{p}, \mathrm{m}}^{(s)}\right)$.

The peculiarity of the standard boundary-value problem is that at any moment of time Fo $\left[\mathrm{FO}_{1} ; \mathrm{FO}_{2}\right]$ between the surfaces $\eta=\bar{r}_{1}$ and $\eta=\bar{r}_{2}$ the particle material is in one aggregation state but we shall present the corresponding boundary conditions in the form

$$
\alpha_{1} u_{p}+\beta_{1}\left(\partial u_{p} / \partial \eta\right)=\gamma_{1} \text { for } \eta=\bar{r}_{1} \quad \alpha_{2} u_{p}+\beta_{2}\left(\partial u_{p} / \partial \eta\right)=\gamma_{2} \text { for } n=\bar{r}_{2}
$$

in this case $\alpha_{i}^{2}+\beta_{i}^{2}>0, i=1,2$.

We shall introduce into consideration the set of control physical volumes (CFV) having compared to the $i-t h C F V$ the sphere layer with the coordinates of internal and external surfaces $\eta_{i-1}, \eta_{i}=\eta_{i-1}+\Delta \eta, i=\overline{T, N}$ where $\Delta \eta=\left(\bar{r}_{2}-\bar{r}_{1}\right) / N$, $n_{0}=\bar{r}_{1}$. We shall integrate (1) in the limits of the $i-t h \mathrm{CFV}$. We shall have 


$$
\overline{\left[\frac{d}{d u_{p}}\left(\bar{p}_{p} \bar{c}_{p} u_{p}\right)\right]_{1}} \int_{\eta_{i-1}}^{\eta_{i}} \frac{\partial u_{p}}{\partial F o} \eta^{2} d \eta=\left(\eta^{2} \bar{\lambda}_{p} \partial u_{p} / \partial \eta\right)_{\eta=\eta_{1}}-\left(\eta^{2} \bar{\lambda}_{p} \partial u_{p} / \partial \eta\right)_{n=\eta_{i-1}},
$$

where the upper bar of expression in square brackets means its averaging over the variable $n$. Taking into account the dependence of lower and upper limits of integration versus time in the general case we shall reduce (3) to the form

$$
d \bar{u}_{P, i} / d F O=\left(J_{i}-J_{i-1}\right) / v_{i} \text {, }
$$

where $\bar{u}_{p, i}$ is the mean value of the function within the $i-t h \mathrm{CFV} ; \nabla_{i}=\left(n_{i}^{3}-\eta_{i-1}^{3}\right) / 3$ is the volume of $i-t h$ CFV; the function $J_{i-\alpha}, \alpha=0,1$ is determined by the expression

$$
J_{i-\alpha}=\left[\tilde{\lambda}_{p, 1-\alpha}\left(\frac{\partial u_{p}}{\partial \eta}\right)_{n=n_{i-\alpha}}+\left(u_{p, i-\alpha}-\bar{u}_{p, i}\right) \frac{1-\alpha}{N} \frac{d}{d F_{0}}\left(\bar{r}_{2}-\bar{r}_{1}\right)\right] n_{i-\alpha}^{2},
$$

where the parameter $\tilde{\lambda}_{p, i-\alpha}=\bar{\lambda}_{p, i-\alpha} /\left[\frac{d}{d F o}\left(\bar{\rho}_{p} \bar{c}_{p} v_{p}\right)\right]_{i}$, but its denominator in the general case depends on $i$. In particular, if $\bar{p}_{p} \bar{c}_{p}=$ const, then $\frac{d}{d U_{p}}\left(\bar{p}_{p} \bar{c}_{p} u_{p}\right)=\bar{\rho}_{p} \bar{c}_{p}$ and $\tilde{\lambda}_{p}=\bar{\lambda}_{p} /\left(\bar{p}_{p} \bar{c}_{p}\right)$.

Note that Eq. (4) with due account of (5) is an absolutely exact presentation of the initial equation (1). Hence, if an efficient procedure is available, which allows by the known mean values $\left\{\bar{v}_{p}, i\right\}=1$ of the function $u_{p}(F o, n)$ to restore $i t s$ distribution in the region $n \in\left[\bar{r}_{1}\left(F_{O}\right) ; \bar{r}_{2}\right.$ (Fo) $]$ for any fixed $F$, then integration of the boundary-value problem for equation in partial derivatives is reduced to integration of Cauchy problem for the system $\mathrm{N}$ of ordinary differential equations relative to $\left\{\bar{U}_{\mathrm{p}, i}(\mathrm{Fo})\right\}_{i=1}^{i=N}$. To this end, the solution $u_{p}(F \circ, n)$ to be determined for the $i-t h C F V$ is presented in the form

$$
u_{p}\left(F_{0}, \eta\right) \approx P_{i}\left(F_{0}, \eta\right) \equiv a_{0}^{(i)}\left(F_{0}\right)+a_{1}^{(i)}\left(F_{0}\right)\left(\eta_{i}-\eta\right)+a_{2}^{(i)}\left(F_{0}, \eta\right)\left(n_{i}-\eta\right)^{2} \text {. }
$$

In this case using the boundary conditions (2), requirements $\bar{u}_{p},=\bar{P}_{i}, i=\overline{1, N}$, as well as assuming continuity $P_{i}$ and $(\partial P / \partial \eta)_{i}$ for adjacent CFVs we have obtained in (ref. 3 ) a correct procedure of finding the coefficients $\left\{a_{0}^{(i)}, a_{1}^{(i)}, a_{2}^{(i)}\right\} \begin{aligned} & i=N \\ & i=1\end{aligned}$.

The results of testing of the developed numerical method which are reported in (ref. 3) indicated its high efficiency. In particular, it has been found that the results of calculations coincide with an accuracy, which is rather high for practice, beginning from the division number $\mathrm{N}=3$ in each phase. All this increases the prompt computational experiment using Lagrangian models. The subsystem of conversational simulating complex for stochastic Lagrangian modelling of disperse components in high-temperature gas flows with due account of complex aggregation state of the particles is based on the developed method.

Eulerian models are based on the representation of an aggregation of particles moving in the flow as a continuum, and heterogeneous flow is considered generally as two interpenetrating and interacting continua. The possibility of the Eulerian description of disperse phase is related to the fulfilment of two conditions: 1) size of individual particles should be much less than the specific linear flow scale; 2) their concentration should be sufficiently high to assign to each point of the space occupied by the particles a certain density, velocity, temperature etc. upon averaging with respect to a small control volume which is defined by specific size of the system. The advantage of the models using the Eulerian approach to the description of gas and disperse phases is the relative simple account of turbulent additive transport. They enable natural generalization for the case of polydisperse particle composition and moreover interparticle collisions can be readily taken into account.

The use of Eulerian approach allows us relatively easy to take into account both direct and inverse interactions between carrying flow and particles of the additive in averaged and fluctuating motions. However numerical methods applied to solve substanee transport equations exhibit the scheme viscosity, and the computational process is of iterative nature due to their nonlinearity. Hence the comparison between the possibilities of Eulerian and Lagrangian models to describe the inertial additive in a jet will ensure better insight into advantages and disadvantages of each method and reveal the fields of their most efficient application (ref. 30).

The available models of high-temperature dust-laden jets (refs. 3, 4, 30-34) which are based on the Eulerian description of disperse phase also require mutual comparison and 
further development with due account of the peculiarities of plasma jet material treatment, including spraying the coatings (different flow regimes in a jet including turbulence extent and its scales; a wide spectrum of sprayed materials and their granulometric composition; powder and gas-carrier flow rate ratio; polydispersity; multicomponent structure; turbulent additive diffusion; effect of the stochasticity of particle injection process on cross scattering in a jet; condensed phase effect on the structure of carrying flow turbulence as well as possible evaporation of particle material on dynamic and thermal nonequilibrium state of phases, etc.).

Some of the above problems are discussed in (refs. 3-5, 30, 34). Particularly in (refs. 3, 34) the Euler model of high-temperature jet with an additive of inertial particles has been suggested which allowed to take into account the stochasticity of the process of powder material injection into the flow. This model is based on a standard $(k-\varepsilon)-$ turbulence model added by equations of gas and particle heat balance as well as kinetic energy of stochastic motion of the particles and corrected with due account of interphase momentum and heat transfer both in averaged and pulsational motions of the phases. The second subsystem of conversational simulating complex described in (ref. 3) is used as software for Eulerian simulation of the class of two-dimensional boundary layer type problems.

\subsection{Interaction "melted particle-surface"}

The process of sprayed formation is implemented by gradual deposition of separate particles solidifying discretely with high rate on a substrate and then their superposition and subsequent formation of one layer of the bulk material at a time.

The "melted particle-surface" system which is the least affected by uncontrolled factors is the ideal object for numerical modelling of the entire complex of processes for superfast quenching of disperse product while spraying the coatings. Here for correct insight into the mechanisms of the coating afhesion and cohesion as well as the processes responsible for the structure of separate adhered particles it is necessary to investigate unsteady-state conjugate convective-conductive heat transfer with simultaneous spread and crystallization of a particle of the melt consisting generally of three layers: substrate, intermediate adhesive layer; porous layer -presprayed coating. Some model statements and solutions of this general problem are presented in (refs. 35-37). More strong possibilities are offered at numerical study of the problem in a more general statement, e.g. (ref. 38). In this case we are using Eulerian - Lagrangian approach of direct numerical modelling of local structure of flow (refs. 3, 39). Taking into account (ref. 37) one can single out a number of aspects in the problem concerning the "particle - base" interaction: a) on the assumption of crystallization absence one should determine the velocity field in the melt, metastability parameter $\mathrm{T}=\mathrm{T}_{\mathrm{m}}-\mathrm{T}\left(\mathrm{T}_{\mathrm{m}}\right.$ is the temperature of particle material melting), cooling rate, time when the region is subjected to supercooling, sizes of metastability regions; b) investigation of processes on the "melt - substrate" boundary (adhesion, substrate melting at contact spot with particle, mutual material diffusion and intermetallide formation, effect of substrate roughness and etc.); c) prediction of nucleation probability, rate of nucleus growth, size of critical nuclei, attainable supercoolings.

However even without solving the stated problem completely, one can, having simplified somewhat the initial statement, obtain one of the most important characteristic of interaction i.e. temperature $T_{k}$ at the critical point which without account of convection and phase transitions for the "melt - solid body" halfspaces are, as known, represented in the form $\mathrm{T}_{\mathrm{kO}}=\left(\mathrm{T}_{10} \mathrm{~K}_{E}+\mathrm{T}_{20}\right) /\left(1+\mathrm{K}_{E}\right)$, where $\mathrm{T}_{10}, \mathrm{~T}_{20}$ are the initial temperatures of melt and substrate; $K_{\varepsilon}=\sqrt{\frac{\rho_{1} C_{1} \lambda_{1}}{\rho_{2} C_{2} \lambda_{2}}} ; \rho_{i}, C_{i}, \lambda_{i}$ are the density, thermal capacity and heat conductivity, respectively $i=1,2$ for melt and substrate, respectively.

To take into account the contribution of melt convection into the contact temperature, one should solve the following problem. Let us consider axisymetric nonisothermal incompressible flow in the vicinity of critical point. Let liquid with temperature $T_{10}$, velocity $U_{p}$ and thermal physical properties independent on temperature flows from infinity onto a semibounded normally placed obstacle with intial temperature $\mathrm{T}_{20}$ and then spreads out along it exchanging by heat.

In (ref. 40) the authors having restricted them selves to the case of ideal spread in the vicinity of critical point (that is valid for metal melts, for which the Prandt 1 numbers $\mathrm{Pr} \approx 10^{-3}-10^{-2}$ ) and considering the potential flow in the vicinity of stagnation point to be quasisteady-state made use of exact solution (ref. 41) characterizing the spread hydrodynamics $W_{z}=-2 \alpha z, W_{r}=\alpha r$, where $W_{z}$, $W_{r}$ are the projections of velocity vector in the cylindrical system of coordinates with origin at the critical point, axis $r$ directed along the surface and axis $z$ oriented upstream; $\alpha$ is the constant. 
Further, neglecting heat conductivity in liquid and substrate along the r-axis in the first approximation they obtained the asymptotic solution

$$
\mathrm{T}_{k}\left(\mathrm{FO}_{0}\right)=\mathrm{T}_{k 0}+\mathrm{PeFO} \frac{\mathrm{K}_{\varepsilon}}{\left(1+\mathrm{K}_{\varepsilon}\right)^{2}} \frac{\mathrm{T}_{10}-\mathrm{T}_{20}}{4 \approx}
$$

which is valid at $P e \ll<1$ and sufficiently small Fo, from which it is evident that the account of convection can change substantially the temperature at the contact point. IIn solution (7) the following designations are used: $P e=U_{p}^{2} /\left(2 \alpha a_{1}\right)$ is the Peclet criterion; Fo $=a_{2}\left(2 \alpha / U_{p}\right)^{2} t$ is the Fourier criterion; $\mathfrak{z}=a_{2} / a_{1} ; a_{i}=\lambda_{i} /\left(\rho_{i} C_{i}\right), i=1,2 ; t$ is the time.

An approach to investigation of contact heat transfer problems which allowed to take off the above restrictions on $\mathrm{Pe}$ and $\mathrm{Fo}$ is suggested in (refs. 36, 42). The obtained solution having the form

$$
T_{k}\left(F_{0}\right)=T_{k \neq 0}+\frac{T_{10}-T_{20}}{1+K_{\varepsilon}}\left\{1-\exp \left[-\frac{K_{\varepsilon}}{4\left(1+K_{E}\right)} X\right]\right\} \text {, where } X=P e F \circ / x \text {. }
$$

Expression (8) is sufficiently exact approximation for the contact temperature. Expanding an exponential term in Taylor series in ( 8 ) and restricting oneself to linear term on $P e$, one can readily obtain ( 7 ). Table 2 illustrates an additional contribution of convection $\Delta \mathrm{T}_{\mathrm{k}}$ into the contact temperature for different combinations of melt and substate materials at $\mathrm{X}=1$ that conforms to time $t=D_{p} / U_{p}\left(D_{p}\right.$ is the particle diameter).

\begin{tabular}{|c|c|c|c|c|c|c|c|}
\hline $\begin{array}{l}\text { Particle } \\
\text { Material }\end{array}$ & $\begin{array}{l}\text { Substrate } \\
\text { Material } \\
\end{array}$ & $\begin{array}{l}\mathrm{T}_{10} \\
\mathrm{~K} \\
\end{array}$ & $\begin{array}{l}\mathrm{T}_{20} \\
\mathrm{~K}\end{array}$ & $\mathrm{~K}_{\varepsilon}$ & $\begin{array}{l}\mathrm{T}_{\mathrm{ko}} \\
\mathrm{K}\end{array}$ & $\begin{array}{l}\Delta \mathrm{T}_{\mathrm{k}} \\
\mathrm{K}\end{array}$ & $\mathrm{T}_{\mathrm{k}} / \mathrm{T}_{2, \mathrm{n}}$ \\
\hline $\mathrm{Al}_{2} \mathrm{O}_{3}$ & $\mathrm{Cu}$ & 2300 & 300 & 0.17 & 586.6 & 60.3 & 0.48 \\
\hline $\mathrm{Al}_{2} \mathrm{O}_{3}$ & $\mathrm{Cu}$ & 3800 & 300 & 0.17 & 801.6 & 105.5 & 0.67 \\
\hline $\mathrm{Ni}$ & $\mathrm{Cu}$ & 1728 & 300 & 0.56 & 812.7 & 78.6 & 0.66 \\
\hline $\mathrm{Ni}$ & $\mathrm{Cu}$ & 3653 & 300 & 0.56 & 1503.9 & 184.5 & 1.25 \\
\hline $\mathrm{Al}_{2} \mathrm{O}_{3}$ & $\mathrm{Ni}$ & 2300 & 300 & 0.38 & 847.9 & 96.1 & 0.55 \\
\hline $\mathrm{Al}_{2} \mathrm{O}_{3}$ & $\mathrm{Ni}$ & 3800 & 300 & 0.38 & 1258.9 & 168.2 & 0.82 \\
\hline $\mathrm{Al}_{2} \mathrm{O}_{3}$ & $\mathrm{Al}_{2} \mathrm{O}_{3}$ & 3800 & 300 & 0.49 & 1451.5 & 185.4 & 0.7 \\
\hline $\mathrm{Al}_{2} \mathrm{O}_{3}$ & $\mathrm{Al}_{2} \mathrm{O}_{3}$ & 3800 & 500 & 0.49 & 1585.7 & 174.8 & 0.77 \\
\hline $\mathrm{Al}_{2} \mathrm{O}_{3}$ & $\mathrm{Al}_{2} \mathrm{O}_{3}$ & 3800 & 700 & 0.49 & 1719.9 & 164.2 & 0.82 \\
\hline
\end{tabular}

TABLE 2.

As one can see from the Table 2, the temperature at the "particle-base" contact is substantially lower than the copper melting temperature $\left(T_{k} / T_{2, n л} \leqslant 0.67\right)$ at interaction between copper substrate and strongly superheated (up to boiling temperature) $\mathrm{Al}_{2} \mathrm{O}_{3}$ particles. This apparently accounts for the difficulty which arises at $\mathrm{Al}_{2} \mathrm{O}_{3}$ spraying on copper substrate. At the same time prespraying the nickel sublayer with subsequent deposition of the basic $\mathrm{Al}_{2} \mathrm{O}_{3}$ coating on it, as is seen, may provide more favourable thermophysical conditions for better adhesion between both the intermediate sublayer and substrate (here copper melting under sprayed $\mathrm{Ni}$ particles is possible) and the basic coating and sublayer.

In a number of cases, for example, at spraying the metal oxides one should take into account the melt viscosity at the determination of the contact temperature in the "molten particle substrate" system. To this end, making use of the approach suggested in (ref. 40) one can find the asymptotic solution for $\mathrm{Pe}<<1$ and rather small Fo taking into account the field of viscous liquid velocities in the vicinity of critical point which is known from literature $W_{z}=-\beta z^{2}, W_{r}=\beta r z, \beta=0.5 \alpha U_{p} / \nu_{1}$, where $\nu_{1}$ is the kinematic viscosity of melt. The statement of the corresponding problem of nonstationary conductive - convective heat transfer and the method of its solution are given in (ref. 37). The obtained asymptotic solution is of the form

$$
\mathrm{T}_{\mathrm{k}}(\mathrm{FO})=\mathrm{T}_{k 0}+\frac{2}{3 \sqrt{\pi}} \operatorname{Pe}\left(\frac{\mathrm{Fo}_{0}}{2}\right)^{3 / 2} \frac{\mathrm{K}_{\varepsilon}\left(\mathrm{T}_{10}-\mathrm{T}_{20}\right)}{\left(1+\mathrm{K}_{\varepsilon}\right)^{2}}
$$

where $P e=U_{p}\left(U_{p} / \beta\right) 1 / 2 / a_{1}, F O=B a_{2} t / U_{P}$.

Solutions (7)-(9) of model problems allow to evaluate the contact temperature for a wide class of sprayed materials and substrates. It is well known from the experience of coating 
spraying (refs. 35,43 ) that the mechanical treatment of surface prior to spraying is one of the methods to increase the strength of particle adhesion with the substrate. In the process of such treatment the surface is cleaned and disturbed from the state of thermodynamic equilibrium with the medium. Moreover preliminary treatment makes the substrate surface rough that results in the increase of temperature at contact under sprayed particles on the rough bulges.

In this context it is extremely interesting to study temperature regimes for a number of model rough elements (rectangular bar, wedge, cone, etc.).

In (ref. 44) the analytical numerical investigation of the given problems for constant heat flux q falling onto the surface of a single rough element is performed using Hermition spline - collocation method. In particular, for the most heat stressed regions (bar and widge edges, cone vertex) the solutions are of the form

$$
\text { a) } \mathrm{T}^{*}(\mathrm{t})=\mathrm{T}_{20}+\frac{2 \mathrm{q}}{\lambda_{2}}\left(\frac{\mathrm{a}_{2} \mathrm{t}}{1}+\sqrt{\frac{\mathrm{a}_{2} \mathrm{t}}{3}}+\frac{1}{12}\right), 0 \leqslant t \leqslant \mathrm{~h}^{2} /\left(12 \mathrm{a}_{2}\right) \text {, }
$$

where $1, \mathrm{~h}$ are the width and height of the bar;

b) $T^{*}(t)=T_{20}+\frac{4}{3 \sqrt{3}} \frac{q \sqrt{a_{2} t}}{\lambda_{2}} \frac{\sin \varphi_{0}}{\varphi_{0}} \frac{\left(6+\sin ^{2} \varphi_{0}\right)}{\left(1+2 \sin ^{2} \varphi_{0}\right)}, 0 \leqslant t \leqslant R^{2} \sin ^{2} \varphi_{0} /\left(12 a_{2}\right)$,

where $\varphi_{0}$ is half of the opening of the wedge; $R$ is the length of its generatrix;

c) $\mathrm{T}^{*}(t)=\mathrm{T}_{20}+\frac{2}{\sqrt{3}} \frac{\mathrm{q} \sqrt{\mathrm{a}_{2} t}}{\lambda_{2}} \frac{\sin ^{2} \varphi_{0}}{\left(1-\cos \varphi_{0}\right)} \frac{\left(3+\sin ^{2} \varphi_{0}\right)}{\left(1+3 \sin ^{2} \varphi_{0}\right)}, 0 \leqslant t \leqslant \mathrm{R}^{2} \sin ^{2} \varphi_{0} /\left(12 \mathrm{a}_{2}\right)$,

where, as above, $\varphi_{O}, R$ are half of the opening of the cone and the length of its generatrix.

The analysis of the obtained solutions shows that under other equal conditions at the "particle - base" interaction the temperature in microbulges can be substantially higher than that at the points of contact with ideally smooth surface. The latter results in the increased thermal activation bf rough elements and at corresponding velocity and particle temperature leads to their melting that may cause the increase of local adhesion.

The results presented confirm, to all appearances, the necessity of or further development of available thermophysical and hydrodynamic fundamentals of the "molten particle - surface" interaction with the purpose to correlate more closely the individual links of "plasmatron dust jet - surface" chain.

\section{AN EXAMPLE OF COMPLEX EXPERIMENT REALIZATION UNDER COATING FORMATION BY TURBULENT PLASMA JET}

The fused electrocorundum of two fractions such as 20-28 mcm (M28) and 50-63 mcm (M63), which is the $\alpha$-phase of aluminium oxide, was chosen as object of investigation similar to the (refs. 1, 2, 45). Such choice is due to the fact that electrocorundum does not react with the ambient and the plasma forming gases, and phase transitions are practically limited to the formation of $\alpha, \nexists$ and $\gamma$ phase and identified readily by petrographic methods. Besides realtively low thermal conductivity, high melting temperature of this material under the conditions of inhomogeneous velocity fields and enthalpy of turbulent flow allow to obtain easily the particles in all aggregation states.

The plasmatron with self-stabilizing arc length and supply of disperse phase to the region of its anode spot was used in the experiments as generator of high-temperature turbulent gas disperse flow that provided the melting of the most particles of different fractions up to the plasmatron exit nozzle and the decreased effect of nonsymmetric flow of cold carrying gas on the structure of jet flow.

The experimental investigation of generated flow of high-temperature gas and behaviour of disperse phase in it was carried out on a computer-based experimental bench (refs. 5, 6).

Initially the investigation of single phase plasma jet at fixed regime parameters of plasmatron ( $I=300 \mathrm{~A}, \mathrm{P}=18 \mathrm{~kW}, \mathrm{G}_{\mathrm{g}}=2 \mathrm{~g} / \mathrm{s}, \mathrm{Ar}-90 \%, \mathrm{~N}_{2}-10 \%$ ) was carried out using the computer-aided enthalpy probe, plasma tomograph and spectroscopy. 


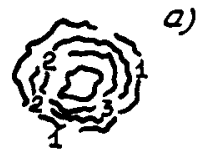

$\bar{\Sigma}=1, T_{\max }=10^{4} \mathrm{~K}$

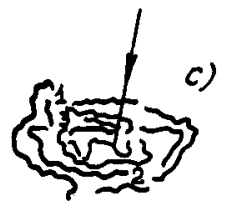

$Z=1, T_{\max }=9.6 \cdot 10^{3} \mathrm{~K}$

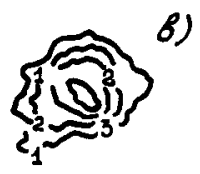

$\overline{1}=2, T_{\max }=10^{4} \mathrm{~K}$

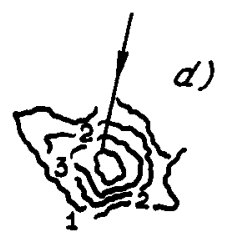

Ta $=2, T_{\text {max }}=8.5 \cdot 10^{3} \mathrm{~K}$
Fig. 7. Fields of the coefficient of turbulent plasma jet emission $\left(\Delta t=10^{-3} \mathrm{~s}\right)$ : $a, b$ - wi thout cold gas injection; $c$, d - with injection.

Fig. $7 \mathrm{a}, \mathrm{b}$ shows the data characterizing the temperature fields near the exit nozzle of the plazmatron which have been obtained using a tomograph. One can see that plasma jet in the absence of powder and carrier gas in the high-temperature powder core had an axial symmetry in the first approximation. This simplified essentially the problem of further detailed investigation into velocity, temperature and gas composition fields by means of enthalpy probe (Fig. 8). On the contrary, with the presence of carrier gas, the flow rate of which corresponded to the conditions of powder injection, the jet deforms and is no longer axisymetric (Fig. $7 \mathrm{~b}, \mathrm{c}$ ), and even for the distance $z=2$ a pronounced effect of cold carrier gas is observed.
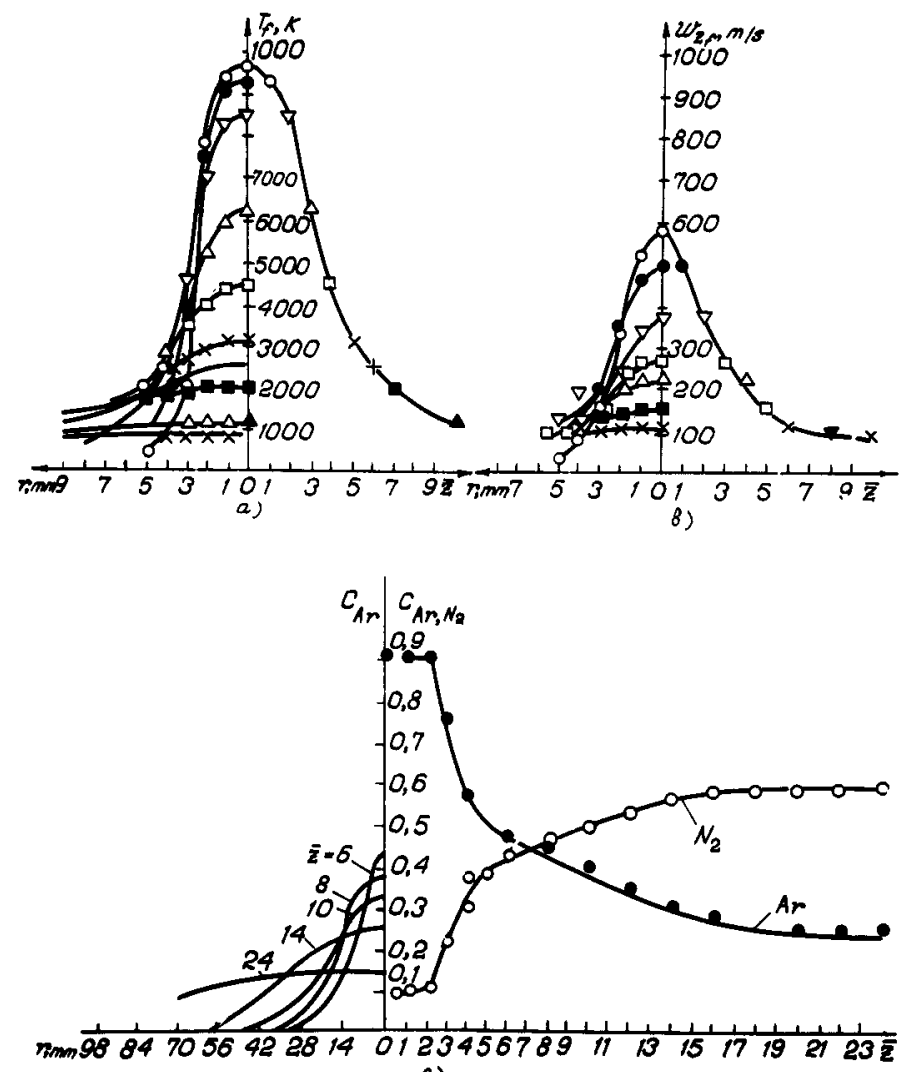

c)

Fig. 8. Radial and axial distributions of gas dynamic nonloaded jet parameters: a - temperature; $b$ - velocity; c - gas component concentrations. 


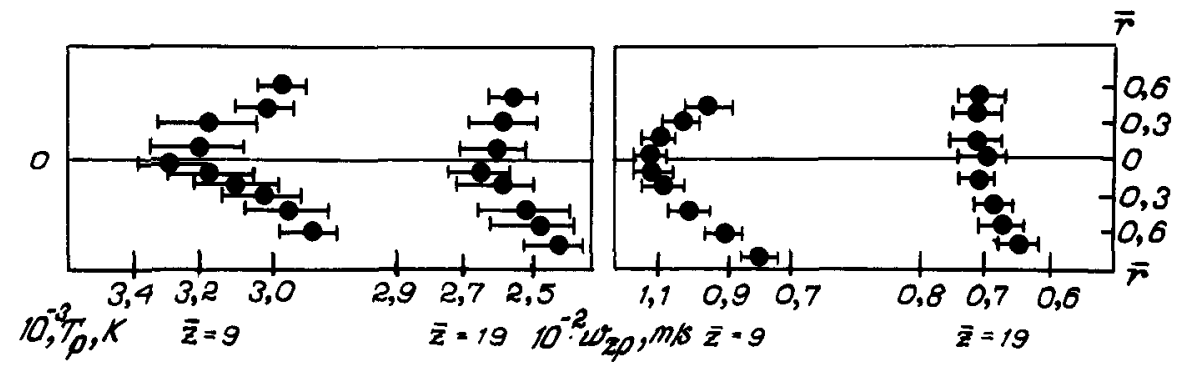

Fig. 9. Temperature and velocity distributions for particles of fraction M.163 in two sections of a jet $\left(z=z / D_{c}, r=r / D_{C}, D_{c}-p\right.$ lasmatron nozzle diameter).

The powder material was injected into a "nozzle-anode" channel, and standard one-sided introduction of particles into plasma flow was used. The method (refs. 14, 15) was employed for measuring the velocity and temperature of $\mathrm{Al}_{2} \mathrm{O}_{3}$ particles in a dust-laden plasma jet. The validity of experimental data (Fig. 9) is confirmed by model calculations of $\mathrm{Al}_{2} \mathrm{O}_{3}$ particle behaviour in the field of gas dynamic parameters of plasma jet, which is known from the experiment. It is shown that it is necessary to take into account the gradient character of particle heating for good agreement between calculated and measured temperatures of the particle surface. This is of high priority primarily for the particles of powder of fraction $\mathrm{M} 63$. The results of joint physical and computational experiments allow to correlate the inhomogeneity of sprayed material structure with the inhomogeneity of conditions of interphase momentum and heat transfer. The results of computational experiment as well as investigation of coating structure have shown that liquid particles which are completely molten, particles with hard nonmolten core and molten external shell, particles with hard core and liquid intermediate and hard external shell, particles with liquid core and hard external shell may participate simultaneously in its formation.

The presence of particles which are in different aggregation states in gas disperse flow to the moment of collision with the base and their participation in coating formation are the important factors defining the character and degree of structural and mechanical inhomogeneity of materials which are obtained by the methods of gas thermal spraying (ref. 46).

In this context of interest is the degree of structural inhomogeneity of the material forming the first monolayer of particles without forming the continuous coating. This detailed information one can find in (ref. 2). Its analysis shows that the disks with a roll on the periphery and semispherical or granular formation in the centre are the basic structural elem in the first monolayer of sprayed material. At the same time the portion of particles of different types depends substantially on the location in the spraying, spot. The latter, in its turn, is defined by the qualitative ratio of the number of particles which are in different aggregation states at the moment of collision with the base and hence, the spraying regime, granulometric composition and physical properties of sprayed disperse material as well as the state and properties of the base. The enumerated factors define also such an important structural characteristic of sprayed materials as porosity.

One of the factors, to which porosity of sprayed $\mathrm{Al}_{2} \mathrm{O}_{3}$ may be related, is the presence of gaps at the places of particle adherence due to the formation of dendrite structure and corresponding microrelief on the surface of particles at solidification as well as voids which appear between separate undermolten particles.

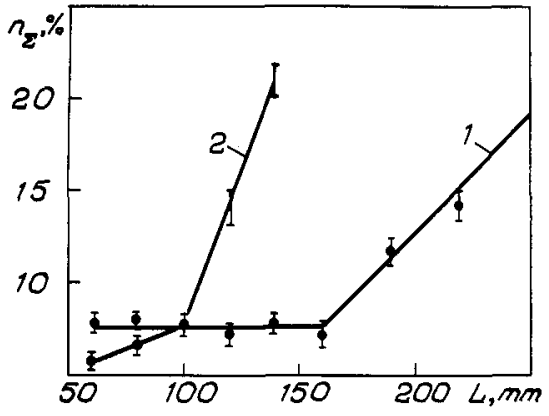

Fig. 10. Variation in the degree of open porosity depending on spraying distance: 1 - for fraction iif3; 2 - for fraction il28. 
It has been found that the dependences of degree of open porosity on the spraying distance for all investigated values of plasmatron operating power have the characteristic point of inflection (Fig. 10).

While using the fine powder M28, the inflection point corresponds to spraying distance $100-120 \mathrm{~mm}$, but while using more coarse powder $\mathrm{M} 63$, it corresponds to spraying distance $160-170 \mathrm{~mm}$ and the rate of porosity increase in the region behind the inflection point exceeds the corresponding values by more than orders of magnitude in the region ahead of the inflection point. The presence of inflection point is accounted for by the change of mechanism of coating formation. When spraying from small distances, the coating material forms from the particles, the overwhelming majority of which is'in a completely molten state. With the increase of spraying distance many molten particles solidify from the surface that results in the increase of coating porosity.

\section{CONCLUSION}

The state of art of apparatus development for thermal spraying, diagnostics and modeliing the gas and gas-disperse flows, investigations into structure and properties of disperse materials and coatings allows the realization of the complex experiment with the purpose to obtain a reliable information on the processes affecting mostly the structure and properties of sprayed materials and coatings. The realization of the complex experiment gives a possibility to make a substantiated choice of the parameters concerning spraying process owing to which the material with optimal preset properties is obtained.

To carry out the analogous complex of investigations concerning spraying the metals, alloys and materials which permit chemical reactions, it is necessary to provide additionally the possibility of the ambient and gas flow component control as well as quantitative analysis of interaction product content inside the sprayed material and investigation of its phase composition. All the problems can be solved at present using the available apparatus and further development of the conception of joint physical and computational experiments.

One can see from the statement of the problem and requirements to subsystems providing complex experiment that the complex and multifunctional apparatus is necessary for its realization.

The problem of organization of complex experiment in the gas thermal spraying can be solved by several possible ways corresponding to different scope of equipment, attained level of knowledge and development of investigation methods. Thus, for example, the complex experiment can be realized by conducting separate technological, material science, physical and computational experiments using independent subsystems (complexes of equipment) isolated with respect to location. In this case to conduct the complex experiment one should provide: regorous correlation with respect to the main parameters of spraying process; identical equipment in technological and diagnostical parts of the experiments as well as the identical conditions of their performance.

The highest stage of the complex experiment development is the application of all subsystems united by location and time with connection to a general complex of computational means for collection, acquisition, mapping and processing of data and experimental control.

\section{REFERENCES}

1. O.P. Solonenko, V.P. Lyagushkin, P.Yu. Pekshev and V.A. Safiullin, in Generatsiya potokov electrodugovoi plazmy (ed. by V.E. Nakoryakov) 359-382, ITF SO AN SSSR, Novosibirsk (1987).

2. V.P. Lyagushkin, O.P. Solonenko, P.Yu. Pekshev and V.A. Safiuliin, Proc. of Intern. Workshop "High-Temperature Dust-Laden Jets in the Processes of Treatment of Powder Materials!, ITF SO AN SSSR, Novosibirsk, 75-84 (1988).

3. M.F. Zhukov and O.P. Solonenko, High-Temperature Dust-Iaden Jets in the Processes of Treatment of Powder Materials, ITF SO AN SSSR, Novosibirsk (1989) (to be published).

4. M.F. Zhukov and O.P. Solonenko, Izv. SO AN SSSR, Ser. tech. nauk, iss. 3, 69-86 (1987).

5. M.F. Zhukov, V.P. Lyagushkin and O.P. Solonenko, Preprint N 145-86, ITF SO AN SSSR, Novosibirsk (1986).

6. M.F. Zhukov, V.P. Lyagushkin and O.P. Solonenko, 8th Intern. Symp. on Plasma Chemistry, Tokyo, Japan, 4, 1995-1999 (1987).

7. A.G. Zavarzin, G.M. Krylov, V.P. Lyagushkin, O.P. Solonenko and V.G. Shatokhin, Proc. of X Al1-Union Conf. on Gen. of Low-Temp. P1., Kaunas, 2, 141 (1986).

8. Theory of thermal electric arc plasma. Part 2. Nonstationary processes and radiative heat transfer in the thermal plasma (ed. by M.F. Zhukov and A.S. Koroteev) Nauka, Novosibirsk (1987). 
9. N.G. Preobrajenski and V.V. Pickalov, Nonstabile problems of plasma diagnostıcs, Nauka, Novosibirsk (1982).

10. T.S. Melnikova and V.V. Pickalov, Beitr. Plasma-phys., Bd. 22, H. 2, 171-180 (1982).

11. J.F. Coudert, M. Vardelle, A. Vardelle and P. Fauchais, in Generatsiya potokov electrodugovoi plazmy (ed. by V.E. Nakoryakov), 397-427, ITF SO AN SSSR, Novosibirsk (1987).

12. D. Gravelle, M. Beaulieu, C. Carlor et al., 6th Intern. Symp. on Plasma Chemistry, Montrea1, Canada, 1, 108 (1983).

13. O.V. Filonin, L.P. Murkin and M.A. Levchenko, 10th Siberian Workshop on spectroscopy, Tomsk, 111 (1981).

14. V.P. Lyagushkin, O.P. Solonenko, Yu.L. Stankevich et a1., Proc. of IX Al1-Union Conf. on Gen. of Low-Temp. P1., Frunze, 272 (1983).

15. V.P. Lyagushkin and O.P. Solonenko, 7 th Symp. on Plasma Chemistry, Eindhoven, Netherlands, 3, 730-735 (1985).

16. T. Yamada, M. Yoshimura and S. Somiya, High Temp. - High Pressures, 18, 4, 377-388 (1986).

17. J.-P. Hiernaut, R. Beukers, M. Hoch, T. Matsui and R.W. Ohse, High Temp. - High Pressures, $18,6,627-633(1986)$.

18. A.A. Emelyanov, N.A. Rubtsov and M.N. Dulin, Proc. of Intern. Workshop "High - Temperature Dust-Laden Jets in the Processes of Treatment of Powder Materials", ITF SO AN SSSR, Novosibirsk, (1988).

19. 0.P. Solonenko, Proc. of Intern. Workshop "High - Temperature Dust-Laden Jets in the Processes of Treatment of Powder Materials", ITF SO AN SSSR, Novosibirsk, 31-36 (1988).

20. A. Donchev, Optimal control systems: perturbations, approximations and sensitivity analysis, Moscow (1987).

21. A.I. Ruban, Identification and sensitivity of complex systems, Tomsk (1981).

22. O.P. Solonenko and A.I. Sorokin, IzV. SO AN SSSR, Ser. tech. nauk (1990) (to be published).

23. E. Pfender, Pure and App1. Chemistry, 57, 9, 1179-1195 (1985).

24. A.V. Donskoy and V.S. Klubnikin, Electric plasma processes and installations in mechanical engineering, Mashinostroyeniye, Leningrad (1979).

25. M.I. Boulos, Pure and App1. Chemistry, 57, 9, 1321-1352 (1985).

26. M. Vardelle, A. Vardelle and P. Fauchais, Proc. 10th Intern. Thermal Spraying Conf., Essen, 88-92 (1983).

27. G.A. Dorfman and V.V. Zhakhov, Phys, and Chem. of Material Treatment, 1, 52-56 (1976).

28. S.V. Dresvin, A.V. Donskoy, V.M. Goldfarb and V.S. Klubnikin, Physics and techniques of low-temperature plasma, Atomizdat, Moscow (1972).

29. J.K. Fiszdon, Int. J. Heat Mass Transfer, 22, 5, 749-761 (1979).

30. D. Miloevich, O.P. Solonenko and G.M. Krylov, in Transport Processes on One- and Two-Phase Media (ed. by S.S. Kutateladze) 70-80, ITF SO AN SSSR, Novosibirsk (1986).

31. Mathematical modelling of electric arc (ed, by V.S. Enge1sht) Ilem, Frunze (1983).

32. I.Ya. Yatskar, Abstr., Phys.-Math. Sci. Cand. Thesis, ITF SO AN SSSR, Novosibirsk (1984).

33. G.M. Krylov, Abstr., Tech. Sci. Cand. Thesis, ITF SO AN SSSR, Novosibirsk (1987).

34. G.M. Krylov and O.P. Solonenko, 8th Intern. Symp. on Plasma Chemistry, Tokyo, Japan, 1, 1952-1957 (1987).

35. V.V. Kudinov and V.M. Ivanov, Plasma spraying of refractory Coatings, Mashinostroyenie, Moscow (1981).

36. B.N. Devyatov, O.P. Solonenko and A.I. Fedorchenko, 8th Intern. Symp. on Plasma Chemistry, Tokyo, Japan, 4 , 1952-1957 (1987).

37. O.P. Solonenko and A.I. Fedorchenko, Izv. So AN SSSR, Ser. tech. nauk, iss, 2, 76-87 (1987).

38. O.P. Solonenko and A.I. Fedorchenko, Proc. of Workshop "Theoretical and Experimenta1 Problems of "Particle-Surface" Interaction", Kiev, 15-25 (1988).

39. O.P. Solonenko and A.I. Fedorchenko, Proc. 13th Scientific and Methodological Seminar on Ship Hydrodynamics, Varna, 2-5 Oct., 1984, 3 , 104-1-104-8 (1984).

40. O.P. Solonenko and A.I. Fedorchenko, Izv. SO AN SSSR, Ser. tech. nauk, iss. 3, 21-25 (1986).

41. G. Shlikhting, Theory of Boundary Layer, Nauka, Moscow (1969).

42. B.N. Devyatov, O.P. Solonenko and A.I. Fedorchenko, Izv. SO AN SSSR, Ser. tech. nauk, iss. 5, 88-94 (1987).

43. A. Khasui, Spraying Technique, Mashinostroyeniye, Moscow (1975).

44. V.V. Deineko, O.P. Solonenko and A.I. Fedorchenko, Proc. of Intern. Conf. on Plasma Science and Technology, Beijing, China, 135-140 (1986).

45. V.P. Lyagushkin, O.P. Solonenko, P.Yu. Pekshev and V.A. Safiullin, 8th Intern. Symp. on Plasma Chemistry, Tokyo, Japan, 4, 1964-1969 (1987).

46. V.V. Kudinov, A.A. Puzanov and A.P. Zamzhbitsky, Optics of Plasma Coating, Nauka, Moscow (1981). 